\title{
Oritavancin for the treatment of acute bacterial skin and skin structure infections: an evidence-based review
}

This article was published in the following Dove Press journal:

Core Evidence

II February 2015

Number of times this article has been viewed

\section{Joumana Kmeid}

Zeina A Kanafani

Division of Infectious Diseases, Department of Internal Medicine, American University of Beirut Medical Center, Beirut, Lebanon
Correspondence: Zeina A Kanafani Division of Infectious Diseases, Department of Internal Medicine, American University of Beirut Medical Center, Cairo Street, PO Box II-0236/IID,

Riad El Solh I I 07 2020,

Beirut, Lebanon

Tel +96 I | 350000 Ext 4747

Fax +96| | 370814

Email zk10@aub.edu.lb
Abstract: The emergence of resistance to glycopeptide antibiotics such as vancomycin and teicoplanin among Gram-positive bacteria has spurred the search for second-generation drugs of this class. Oritavancin, a promising novel, second-generation, semisynthetic lipoglycopeptide, is distinguished by two mechanisms of action: inhibition of cell wall synthesis and disruption of the cell membrane. This dual mechanism of action has increased the activity of oritavancin against vancomycin-resistant Gram-positive bacteria compared to other glycopeptides. Oritavancin has a concentration-dependent and rapid bactericidal activity against Gram-positive bacteria, particularly enterococci, contrary to vancomycin and teicoplanin, which exhibit bacteriostatic activity. It has a long half-life of about 195.4 hours and is slowly eliminated by the liver and kidneys, allowing once-daily dosing. Oritavancin has demonstrated preliminary safety and efficacy in Phase I and Phase II clinical trials. It was recently shown to be noninferior to vancomycin in a large Phase III randomized, double-blind clinical trial. To date, adverse events have been mild and limited, the most common being administration site complaints, headache, and nausea. Oritavancin appears to be a promising antimicrobial alternative to vancomycin with additional activity against Staphylococcus and Enterococcus isolates resistant to vancomycin and a more convenient way of administration.

Keywords: skin infection, Staphylococcus aureus, Gram-positive organisms

Core evidence clinical impact summary for oritavancin in acute bacterial skin and skin structure infections

\begin{tabular}{|c|c|c|}
\hline Outcome measure & Evidence & Implications \\
\hline \multicolumn{3}{|l|}{ Disease-oriented evidence } \\
\hline Primary efficacy outcome at ECE & Substantial & $\begin{array}{l}\text { A single dose of oritavancin is non-inferior to } \\
\text { vancomycin given twice daily for a period of } 7 \\
\text { to } 10 \text { days }\end{array}$ \\
\hline $\begin{array}{l}\text { Investigator-assessed clinical } \\
\text { cure at PTE }\end{array}$ & Substantial & $\begin{array}{l}\text { Clinical cure at PTE was similar with oritavancin } \\
\text { and with vancomycin }\end{array}$ \\
\hline $\begin{array}{l}\text { Lesion size reduction } \geq 20 \% \\
\text { at } E C E\end{array}$ & Substantial & $\begin{array}{l}\text { Patients in the oritavancin group had similar } \\
\text { reduction in lesion size at ECE compared to } \\
\text { those in the oritavancin group }\end{array}$ \\
\hline $\begin{array}{l}\text { Subpopulation with MRSA } \\
\text { infection }\end{array}$ & Moderate & $\begin{array}{l}\text { Similar efficacy of oritavancin and vancomycin } \\
\text { for the primary and secondary endpoints }\end{array}$ \\
\hline \multicolumn{3}{|l|}{ Patient-oriented evidence } \\
\hline Adverse events & Moderate & $\begin{array}{l}\text { Incidence of adverse events was similar in the } \\
\text { oritavancin and vancomycin treatment groups }\end{array}$ \\
\hline Drug discontinuation & Moderate & $\begin{array}{l}\text { Rate of drug discontinuation due to adverse } \\
\text { events was lower in the oritavancin group } \\
\text { (Continued) }\end{array}$ \\
\hline
\end{tabular}




\begin{tabular}{|c|c|c|}
\hline \multicolumn{3}{|l|}{ (Continued) } \\
\hline Outcome measure & Evidence & Implications \\
\hline Compliance & Substantial & $\begin{array}{l}\text { Single dose oritavancin entails better compliance } \\
\text { compared to a } 7 \text { to } 10 \text { treatment duration with } \\
\text { vancomycin }\end{array}$ \\
\hline Mortality & Moderate & $\begin{array}{l}\text { Mortality rate in the SOLO trials was very low } \\
\text { and did not differ between oritavancin and } \\
\text { vancomycin }\end{array}$ \\
\hline \multicolumn{3}{|l|}{ Economic evidence } \\
\hline Cost effectiveness & Limited & Further studies required \\
\hline
\end{tabular}

\section{Introduction}

Oritavancin (previously LY333328) is a newly introduced glycopeptide whose history dates back to 1996, when Eli Lilly and Company submitted to the US Food and Drug Administration (FDA) an Investigational New Drug Application, following which, several Phase I, II, and III studies were initiated, mainly bacteremia and skin and skin structure infection studies (Figure 1). Then, in 2002, the Investigational New Drug Application was transferred to InterMune, Incorporated, but clinical trials were halted due to infusion-related adverse events in previous trials. Targanta Therapeutics Corporation acquired oritavancin in 2006 and demonstrated that injection-site phlebitis was a side effect frequently observed with most glycopeptides. In 2008, Targanta presented a New Drug Application for oritavancin as an intravenous formulation given once daily for 3 to 7 days for the treatment of complicated skin and soft tissue infections. Oritavancin has since been studied in two Phase III trials, the results of which have been recently published and show oritavancin to be noninferior to vancomycin in skin infections. The current proposed therapeutic use of oritavancin is for the treatment of acute bacterial skin and skin structure infections (ABSSSIs) caused by susceptible Gram-positive bacteria.

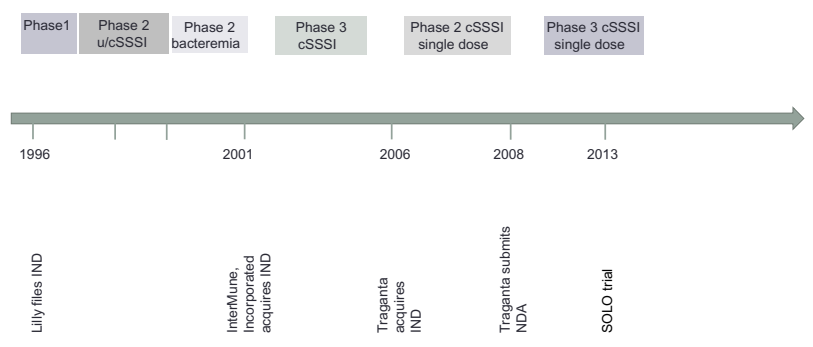

Figure I Developmental history of oritavancin.

Abbreviations: cSSSI, complicated skin and skin structure infections; IND, Investigational New Drug; NDA, New Drug Application.

\section{Methods}

We searched Medline, PubMed, and Embase using the following keywords and MeSH terms: "oritavancin", "LY333328", "bacterial skin infection", and "staphylococcal skin infection". The search resulted in 244 publications until June 2014.

This review will include the most relevant articles, mainly original research articles. Also included in this review are data from abstracts and poster presentations at international conferences and meetings, since oritavancin is a new drug and much of the data in the literature has not yet been published in peer-reviewed journals.

\section{Overview of the drug}

Glycopeptides are antimicrobial agents composed of glycosylated cyclic or polycyclic nonribosomal peptides with activity against Gram-positive organisms. They are produced naturally through fermentation of actinomycetes and act by inhibiting cell wall synthesis by preventing the addition of new units to the peptidoglycan. Vancomycin was the first glycopeptide to be introduced into the market in 1955. Oritavancin diphosphate (LY333328) is a semisynthetic lipoglycopeptide derived from a precursor closely related to vancomycin with a broad antibacterial activity against Gram-positive bacteria, including methicillin- and vancomycin-resistant staphylococci and penicillin-resistant streptococci.

\section{Chemical structure, structure-activity relationships, and mechanism of action}

Oritavancin is derived from the natural glycopeptide chloroeremomycin, an analog of vancomycin (Figure 2). The modified structure contains both hydrophobic and hydrophilic groups and it is classified as a lipoglycopeptide. Oritavancin includes an additional unsubstituted sugar and a lipophilic 


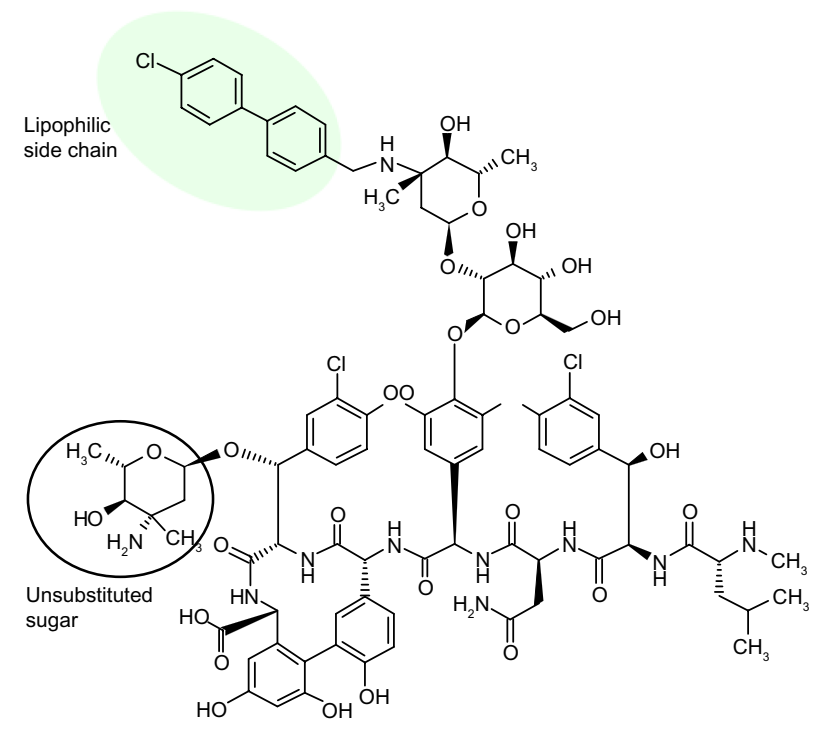

Figure 2 Chemical structure of oritavancin.

side chain not present in vancomycin. The chemical structure and properties of oritavancin result from $\mathrm{N}$-alkylation of the disaccharide amino group in chloroeremomycin.

The peptide backbone interferes with the formation of the bacterial cell wall by binding to the D-alanyl-D-alanine terminal in the peptidoglycan chains of Gram-positive bacteria and by blocking the transglycosylation step of peptidoglycan synthesis. The lipophilic tail provides a prolonged half-life, allowing for once-daily dosing, and modifies the mode of action, conferring a concentrationdependent bactericidal activity.

In addition, oritavancin is able to bind to the cytoplasmic membrane by the alkyl side chain, resulting in enhanced binding to the peptidoglycan residues and an increased activity against vancomycin-resistant enterococci (VRE), vancomycin-intermediate Staphylococcus aureus (VISA), and vancomycin-resistant $S$. aureus strains. This dual mode of action was demonstrated by nuclear magnetic resonance experiments performed by Kim et al, which showed that oritavancin-like glycopeptides (unlike vancomycin-like peptides) have two cell wall binding sites. ${ }^{1}$ Furthermore, oritavancin was shown to have effects on RNA synthesis in addition to its primary mode of action. ${ }^{2}$ This activity was observed in a methicillin-susceptible $S$. aureus (MSSA) laboratory strain, and investigators have linked the loss of the permeability barrier function to inhibition of RNA synthesis. ${ }^{3}$

\section{Pharmacokinetics and pharmacodynamics}

Oritavancin demonstrates concentration-dependent activity ${ }^{4,5}$ and a long post-antibiotic effect both in vitro ${ }^{5}$ and in vivo. ${ }^{6}$
In vitro ${ }^{7}$ and Phase $\mathrm{I}^{8}$ studies have shown that oritavancin accumulates in the lysosomes of macrophages, reaching up to 300-fold intracellular concentration. Once inside the cells, its efflux to the extracellular space is slow. This mechanism accounts for the long half-life of oritavancin and allows intraphagocytic activity against some pathogens that survive within lysosomes, such as $S$. aureus. While vancomycin is bacteriostatic against stationary-phase cells, oritavancin exerts in vitro bactericidal activity against bacteria that are nondividing, those that grow intracellularly, ${ }^{9}$ and those that are in a biofilm state. ${ }^{10-12}$

In Phase I clinical studies in healthy subjects, oritavancin exhibited similar pharmacokinetics whether given in single or multiple doses, with very little drug accumulation over a 24-hour period. ${ }^{13,14}$ The minimum inhibitory concentrations (MICs) for oxacillin-susceptible and -resistant isolates were almost identical, with $\mathrm{MIC}_{50}$ and $\mathrm{MIC}_{90}$ values of 0.06 and $0.12 \mu \mathrm{g} / \mathrm{mL}$, respectively, although the MIC range reached up to $0.25 \mu \mathrm{g} / \mathrm{mL}$.

In Phase II trials, it was shown that oritavancin has comparable pharmacokinetics in patients with skin and soft tissue infections (complicated and uncomplicated) and in healthy volunteers. One exception was that drug clearance was higher in infected patients, although there was no real clinical impact to this observation.

Studies have shown that dose adjustment based on age and renal and liver function is not needed. In fact, the pharmacokinetics of oritavancin are independent of sex, race, and hepatic and renal function. ${ }^{15}$ However, more clinical data are needed to guide the use of oritavancin in these patient groups. Although for single-dose use, weight-based dosing seems unnecessary, dose modification is needed in subjects weighing more than $110 \mathrm{~kg}$ if oritavancin is used in multiple doses. ${ }^{15}$

Fetterly et al used a blister fluid model to simulate the efficacy of oritavancin in treating complicated skin infections in 16 healthy men. ${ }^{16}$ Using two dose regimens ( $200 \mathrm{mg}$ once daily for 3 days or a single $800 \mathrm{mg}$ dose), mean oritavancin concentrations in blister fluid exceeded the oritavancin $\mathrm{MIC}_{90}$ for $S$. aureus strains by at least 1.5 -fold.

Oritavancin has shown synergistic activity with several antibiotics, such as with daptomycin against enterococci, and with gentamicin and linezolid against $S$. aureus, including a VISA and a vancomycin-resistant $S$. aureus strain. ${ }^{17}$ On the other hand, no antagonism has been found between oritavancin and other commonly used antibacterial agents.

Oritavancin is administered through the intravenous route. It has low oral bioavailability due to its high molecular 
weight, which hinders absorption through the gastrointestinal mucosa.

Oritavancin is strongly bound to plasma proteins $(86 \%-90 \%)^{18}$ and is distributed into a variety of tissues, including liver, skin, lungs, and, less so, into kidneys and spleen. $8,13,14,19$

\section{Antimicrobial spectrum}

Oritavancin demonstrates in vitro activity against most Gram-positive and anaerobic bacteria (Table 1). Its spectrum of activity is similar to that of vancomycin and teicoplanin, but is distinguished by its activity against vancomycinresistant organisms. ${ }^{20}$ In addition to the target organisms, oritavancin has in vitro activity against other Gram-positive organisms, including modest activity against species intrinsically resistant to glycopeptides (Lactobacillus, Leuconostoc, and Pediococcus spp.). Oritavancin does not have activity against Gram-negative organisms.

One notable finding from recent in vitro studies is that the activity of oritavancin against $S$. aureus is independent of oxacillin susceptibility, with $\mathrm{MIC}_{90}$ values ranging from 0.06 to $0.25 \mu \mathrm{g} / \mathrm{mL}$. In a longitudinal European study from 2011 to 2013, the activity of oritavancin against $S$. aureus (MSSA and methicillin-resistant $S$. aureus [MRSA]) remained constant over the duration of the study. ${ }^{21}$ These results were confirmed by another study that showed that all except one multidrug-resistant staphylococcal isolate were inhibited by oritavancin at $\leq 0.25 \mu \mathrm{g} / \mathrm{mL}$, with an $\mathrm{MIC}_{50}$ of $0.03 \mu \mathrm{g} / \mathrm{mL}$. A total of $99.3 \%$ of multidrug-resistant (MDR) $S$. aureus isolates were methicillin resistant and had high susceptibility rates to vancomycin $\left(\mathrm{MIC}_{50 / 90}, 1 / 1 \mu \mathrm{g} / \mathrm{mL} ; 100 \%\right.$ susceptible), teicoplanin $\left(\mathrm{MIC}_{50 / 90}, \leq 2 / \leq 2 \mu \mathrm{g} / \mathrm{mL} ; 99 \%\right.$ susceptible), daptomycin $\left(\mathrm{MIC}_{50 / 90}, 0.25 / 0.5 \mu \mathrm{g} / \mathrm{mL}\right.$; 99.8\% susceptible), linezolid $\left(\mathrm{MIC}_{50 / 90}, 1 / 1 \mu \mathrm{g} / \mathrm{mL}\right.$; $99.5 \%$ susceptible), and trimethoprim/sulfamethoxazole $\left(\mathrm{MIC}_{50 / 90}, \leq 0.5 / \leq 0.5 \mu \mathrm{g} / \mathrm{mL} ; 95.0 \%\right.$ susceptible $)$. Oritavancin MICs were twofold higher against $S$. aureus isolates with vancomycin $\mathrm{MIC}=2 \mu \mathrm{g} / \mathrm{mL}$ compared to those against isolates with lower vancomycin MICs.

Oritavancin had equivalent MICs against MDR and non-MDR coagulase-negative staphylococci (CoNS). When tested against MDR CoNS, oritavancin had MICs that were eight- to 32-fold lower than those of daptomycin $\left(\mathrm{MIC}_{50 / 90}, 0.5 / 0.5 \mu \mathrm{g} / \mathrm{mL} ; 100 \%\right.$ susceptible) and linezolid $\left(\mathrm{MIC}_{50 / 90}, 0.5 / 1 \mu \mathrm{g} / \mathrm{mL} ; 98.3 \%\right.$ susceptible), and 32 - to 128 -fold lower than those of vancomycin
$\left(\mathrm{MIC}_{50 / 90}, 2 / 2 \mu \mathrm{g} / \mathrm{mL} ; 100 \%\right.$ susceptible) and teicoplanin $\left(\mathrm{MIC}_{50 / 90}, 4 / 8 \mu \mathrm{g} / \mathrm{mL} ; 74.0 \%\right.$ susceptible $){ }^{22}$

Oritavancin is highly effective against beta-hemolytic streptococci, as evidenced by potent in vitro activity against clinical isolates collected from patients with skin infections in European and Israeli hospitals. ${ }^{22}$

Oritavancin is active against both vancomycin-susceptible and -resistant Enterococcus spp. Unlike telavancin and dalbavancin, which have limited activity against VanA strains, oritavancin retains substantial activity against VanA as well as VanB strains. In a study by Mendes et al, a total of 3,321 isolates of enterococci were recovered from European medical centers between 2009 and 2013. Most of the isolates were Enterococcus faecalis and Enterococcus faecium. Oritavancin demonstrated greater in vitro activity than comparators when tested against this collection of enterococcal isolates, regardless of vancomycin phenotype. Of note, when tested against VanA-phenotype isolates, oritavancin was four- to 16-fold less active than against the vancomycin-susceptible and VanB-phenotype counterparts; however, all isolates were inhibited at $\leq 0.5 \mu \mathrm{g} / \mathrm{mL} .^{23}$

In a study from western European countries in $2011,{ }^{24}$ the authors determined the activity of oritavancin against MRSA, VRE, and beta-hemolytic streptococci recently isolated from ABSSSIs or bacteremia. A total of 866 isolates were collected (204 MRSA, 177 methicillin-resistant CoNS, 101 VRE, 193 Streptococcus agalactiae, and 191 Streptococcus pyogenes). The results showed that oritavancin was very active against MRSA $\left(\right.$ MIC $\left._{50 / 90} 0.03 / 0.06 \mu \mathrm{g} / \mathrm{mL}\right)$, methicillin-resistant CoNS $\left(\mathrm{MIC}_{50 / 90} 0.06 / 0.12 \mu \mathrm{g} / \mathrm{mL}\right), \mathrm{VRE}\left(\mathrm{MIC}_{50 / 90} 0.03 / 0.06 \mu \mathrm{g} / \mathrm{mL}\right)$, $S$. agalactiae $\left(\mathrm{MIC}_{50 / 90} 0.03 / 0.06 \mu \mathrm{g} / \mathrm{mL}\right)$, and $S$. pyogenes $\left(\mathrm{MIC}_{50 / 90} 0.06 / 0.25 \mu \mathrm{g} / \mathrm{mL}\right)$. The highest observed oritavancin MIC was $0.25 \mu \mathrm{g} / \mathrm{mL}^{24}$

The activity of oritavancin against MRSA was evaluated also in the presence of the mec-C gene. Oritavancin's in vitro activity against mec- $C$ MRSA strains was indistinguishable from that against mec- $A$ MRSA strains in both MIC and time-kill assays. In addition, oritavancin demonstrated more potent in vitro activity than comparators against the mec- $C$ strains tested. ${ }^{25}$

In another study, Mendes et al showed that oritavancin exhibited potent activity against the common bacteria causing skin and soft tissue infections, including MDR subsets. ${ }^{26}$ Similar results were presented by Deane et al, ${ }^{27}$ who found that oritavancin maintained a comparable and high level of in vitro activity, regardless of the resistant phenotypes analyzed. This level of activity was several-fold more potent 
Table I In vitro activity of oritavancin against Gram-positive organisms

\begin{tabular}{|c|c|c|}
\hline Organism & Category & MIC range, $\mu \mathrm{g} / \mathrm{mL}$ \\
\hline \multirow[t]{8}{*}{ Staphylococcus aureus } & All & $\leq 0.004-4$ \\
\hline & Oxacillin S & $\leq 0.004-0.5$ \\
\hline & Oxacillin R & $\leq 0.004-4$ \\
\hline & Daptomycin NS & $0.015-1$ \\
\hline & Linezolid NS & $0.06-0.25$ \\
\hline & hVISA & $0.25-1$ \\
\hline & VISA & $0.5-1$ \\
\hline & VRSA & $0.12-0.5$ \\
\hline \multirow[t]{4}{*}{ Staphylococcus epidermidis } & All & $\leq 0.004-2$ \\
\hline & Oxacillin S & $0.008-1$ \\
\hline & Oxacillin R & $\leq 0.004-2$ \\
\hline & VICNS & $0.12-2$ \\
\hline \multirow[t]{3}{*}{ Staphylococcus haemolyticus } & All & $0.008-1$ \\
\hline & Oxacillin S & $0.008-0.12$ \\
\hline & Oxacillin R & $0.015-1$ \\
\hline \multirow[t]{3}{*}{ Streptococcus pyogenes } & All & $0.008-0.5$ \\
\hline & Erythromycin S & $0.008-0.5$ \\
\hline & Erythromycin NS & $0.008-0.25$ \\
\hline \multirow[t]{3}{*}{ Streptococcus agalactiae } & All & $0.03-0.5$ \\
\hline & Erythromycin S & $0.03-0.5$ \\
\hline & Erythromycin NS & $0.03-0.5$ \\
\hline \multirow[t]{3}{*}{ Streptococcus group C } & All & $0.00 \mathrm{I}-0.25$ \\
\hline & Erythromycin S & $0.00 \mathrm{I}-0.25$ \\
\hline & Erythromycin NS & $0.008-0.25$ \\
\hline \multirow[t]{3}{*}{ Streptococcus group G } & All & $0.008-1$ \\
\hline & Erythromycin S & $0.008-1$ \\
\hline & Erythromycin NS & $0.015-0.12$ \\
\hline \multirow[t]{3}{*}{ Streptococcus mitis } & All & $0.015-1$ \\
\hline & Erythromycin S & $0.03-1$ \\
\hline & Erythromycin NS & $0.015-0.5$ \\
\hline Viridans group & All & $0.004-1$ \\
\hline \multirow[t]{2}{*}{ Streptococcus } & Erythromycin NS & $0.004-0.12$ \\
\hline & Erythromycin S & $0.004-0.25$ \\
\hline \multirow[t]{6}{*}{ Enterococcus faecalis } & All & $\leq 0.0005-4$ \\
\hline & Vancomycin S & $\leq 0.0005-0.5$ \\
\hline & Vancomycin NS & $0.015-4$ \\
\hline & Linezolid NS & $0.015-0.5$ \\
\hline & $\operatorname{Van} A$ & $0.03-4$ \\
\hline & VanB & $0.015-0.12$ \\
\hline \multirow[t]{7}{*}{ Enterococcus faecium } & All & $\leq 0.0005-2$ \\
\hline & Vancomycin S & $\leq 0.0005-0.06$ \\
\hline & Vancomycin NS & $\leq 0.0005-2$ \\
\hline & Daptomycin NS & $0.015-0.5$ \\
\hline & Linezolid NS & $0.004-0.25$ \\
\hline & $\operatorname{Van} A$ & $0.004-2$ \\
\hline & VanB & $\leq 0.0005-0.06$ \\
\hline \multirow[t]{3}{*}{ Enterococcus gallinarum } & All & $0.004-0.25$ \\
\hline & Vancomycin S & $0.03-0.03$ \\
\hline & Vancomycin NS & $0.004-0.25$ \\
\hline Clostridium difficile & All & $0.25-1$ \\
\hline Clostridium perfringens & All & $0.25-1$ \\
\hline Lactobacillus spp. & All & $0.004-8$ \\
\hline Peptostreptococcus spp. & All & $\leq 0.004-0.5$ \\
\hline
\end{tabular}

Table I (Continued)

\begin{tabular}{lll}
\hline Organism & Category & MIC range, $\mu \mathrm{g} / \mathbf{m L}$ \\
\hline Propionibacterium acnes & All & $0.12-0.5$ \\
Propionibacterium spp. & All & $0.06-0.25$ \\
\hline Note: Data from Targanta Therapeutics Corporation. & \\
Abbreviations: hVISA, hetero-vancomycin-intermediate & Staphylococcus aureus; \\
MIC, minimum inhibitory concentration; NS, non-susceptible; S, susceptible; \\
R, resistant; VISA, vancomycin-intermediate Staphylococcus aureus; VRSA, vancomycin- \\
resistant Staphylococcus & aureus; VICNS, vancomycin-intermediate coagulase \\
negative staphylococci. &
\end{tabular}

than that of vancomycin, and underscores the strong potential oritavancin has for the treatment of infections caused by these resistant Gram-positive pathogens. ${ }^{27}$

\section{Mechanism of resistance}

While resistance to oritavancin has not been described to date in the clinical setting, two in vitro mechanisms of resistance to oritavancin have been described: the first is via current glycopeptide resistance mechanisms (eg, van operons), and the second is the VISA-type cell wall thickening mechanism. MIC distributions for staphylococcal and enterococcal strains indicate an absence of cross-resistance with resistant phenotypes such as VanA, VanB, VanC, or VISA. ${ }^{28}$

\section{Preclinical studies}

Animal models used to evaluate the effectiveness of oritavancin include a neutropenic thigh infection mouse model (for $S$. aureus and S. pyogenes infections), ${ }^{29}$ a granuloma pouch infection rat model (for MSSA), ${ }^{6}$ a bacteremia mouse model (for $S$. aureus and VRE), ${ }^{30}$ and an endocarditis rabbit model (for MRSA and VRE). ${ }^{31,32}$

In a murine neutropenic thigh model study, ${ }^{29}$ oritavancin was found to be effective in the treatment of complicated skin infections due to $S$. aureus. It was also suggested that using oritavancin in a higher but less frequent dose is more effective than using multiple small doses.

Lehoux et al evaluated oritavancin compared to vancomycin in a rat granuloma pouch model study, simulating skin abscesses that are seen in the human host, ${ }^{6}$ and found that oritavancin for the treatment of $S$. aureus skin infections can achieve the same efficacy at daily or less frequent dosing intervals.

Similarly, endocarditis and bacteremia models showed adequate penetration into vegetations and high eradication rates from blood with oritavancin. ${ }^{30-32}$

\section{Clinical studies}

Oritavancin entered Phase III trials in USA in January 2001. The efficacy of oritavancin in the treatment of skin and skin 
structure infections has been assessed in Phase II and III studies: a Phase II open-label skin and skin structure study (ARRL trial); a Phase II double-blind complicated skin and skin structure infection study (SIMPLIFI trial); and three Phase III randomized, double-blind, active comparator studies in complicated skin and skin structure infection (ARRI, ARRD, and SOLO trials).

The SIMPLIFI Phase II trial included 302 patients who were randomized to one of three treatment arms: the dailydose arm (200 mg for 3 to 7 days), the single-dose arm (1,200 $\mathrm{mg}$ once), or the infrequent-dose arm (initial single dose of $800 \mathrm{mg}$, followed by reassessment on day 5 for the need of an extra dose of $400 \mathrm{mg}$ ). There were no differences in the clinical response rates among the three arms, including the subgroup of patients with infections due to MRSA (daily-dose arm: 72\% [78.3\% for MRSA]; single-dose arm: 81.5\% [73.0\% for MRSA]; and infrequent-dose arm: $77.5 \%$ $[87.0 \%$ for MRSA] $) .{ }^{33}$

The earlier Phase III trials, ARRD and ARRI, used weight-based (200 mg; $300 \mathrm{mg}$ if weight $>110 \mathrm{~kg}$ ) and fixed dosing (200 mg), respectively. Data from these two studies showed that oritavancin given once daily for 3 to 7 days is noninferior to vancomycin/cephalexin given twice daily for 10 to 14 days when treating skin and soft tissue infections caused by Gram-positive bacteria (wound infection, major abscess, or cellulitis). Both clinical and microbiological response rates were similar between oritavancin and the comparator group in all populations and subgroups.

More recently, the results of a Phase III double-blind noninferiority trial (SOLO) were published. ${ }^{34}$ A total of 968 adults with ABSSSI were randomly assigned to receive either one dose of 1,200 mg of oritavancin intravenously or intravenous vancomycin twice daily for 7 to 10 days with serum trough monitoring, and were followed to 60 days. Half of the patients had cellulitis (50\%); the rest had abscesses (30\%) and wound infections (20\%). MRSA and MSSA were isolated in comparable percentages ( $21 \%$ and $23 \%$, respectively). The primary endpoint was a composite of the following: stabilization or improvement in lesion size, defervescence, and no requirement for an alternative antibacterial agent at 48 to 72 hours after administration of oritavancin. Secondary endpoints were defined as the following: clinical cure at 7 to 14 days after end of therapy and a minimum of $20 \%$ reduction in lesion size after 48 to 72 hours of oritavancin administration.

Nine hundred and fifty-four patients $(98.5 \%)$ were included in the modified intent-to-treat analysis (475 patients on oritavancin and 479 patients on vancomycin). The composite primary endpoint occurred in $82.3 \%$ with oritavancin versus
$78.9 \%$ with vancomycin (noninferiority met). An investigatorassessed clinical cure occurred in $79.6 \%$ with oritavancin versus $80 \%$ with vancomycin, while a decrease in lesion area of at least $20 \%$ at 48 to 72 hours was observed in $86.9 \%$ with oritavancin versus $82.9 \%$ with vancomycin. None of the above differences were statistically significant. Efficacy outcomes measured according to type of pathogen were similar (Table 2). The authors concluded that a single dose of oritavancin administered intravenously was noninferior to vancomycin administered twice daily for a period of 7 to 10 days when treating ABSSSI caused by Gram-positive bacteria. ${ }^{34}$

\section{Safety and tolerability}

Collective data from Phase II and III studies have described comparable ${ }^{35}$ or fewer ${ }^{36,37}$ adverse events with oritavancin compared to vancomycin/cephalexin. The most frequently reported side effects were reactions at the site of injection, nausea and vomiting, and pruritus. Adverse events leading to discontinuation of treatment drug were rare. ${ }^{38}$

In another study, which involved healthy subjects receiving oritavancin, ${ }^{13}$ adverse events included transient minimal elevations in liver enzymes (less than three times the upper limit of the normal range for transaminases, and less than two times the upper limit of the normal range for bilirubin). However, no signs of permanent hepatic damage were observed clinically.

Nephrotoxicity, ototoxicity, and QT alterations have not been described to date with oritavancin. ${ }^{39}$ However, the fact that oritavancin is characterized by high intracellular accumulation might suggest potential toxicity to several tissues such as the liver and the lungs. ${ }^{39}$ Thus, close monitoring of the use of oritavancin is required for a complete assessment of the drug's side effects.

In the SOLO trial, adverse events were similar between the two groups, except for nausea, which was more common in the oritavancin group (Table 3). In addition, the incidence of adverse events was similar between treatment groups in patients treated in the outpatient setting $(72.7 \%$ with oritavancin; $70.2 \%$

Table 2 Early clinical cure rates with oritavancin versus vancomycin in patients with SSSI (SOLO I and II trials)

\begin{tabular}{lll}
\hline Pathogen & $\begin{array}{l}\text { Oritavancin } \\
(\mathbf{n}=\mathbf{5 2 9})\end{array}$ & $\begin{array}{l}\text { Vancomycin } \\
(\mathbf{n}=\mathbf{5 3 8})\end{array}$ \\
\hline S. aureus & $388 / 470(82.5 \%)$ & $391 / 468(83.5 \%)$ \\
MRSA & $166 / 204(81.4 \%)$ & $162 / 201(80.6 \%)$ \\
MSSA & $222 / 266(83.5 \%)$ & $229 / 267(85.8 \%)$ \\
Streptococcus spp. & $61 / 79(77.2 \%)$ & $81 / 95(85.3 \%)$ \\
Enterococcus faecalis & $11 / 13(84.6 \%)$ & $10 / 12(83.3 \%)$ \\
\hline
\end{tabular}

Abbreviations: SSSI, skin and skin structure infection; $\mathrm{Cl}$, confidence interval; MRSA, methicillin-resistant S. aureus; MSSA, methicillin-susceptible S. aureus. 
Table 3 Adverse events associated with oritavancin vs. vancomycin (SOLO I and II trials)

\begin{tabular}{lll}
\hline Adverse event & $\begin{array}{l}\text { Oritavancin, } \mathbf{n}(\%) \\
(\mathbf{n}=\mathbf{9 7 6})\end{array}$ & $\begin{array}{l}\text { Vancomycin, } \mathbf{n}(\%) \\
(\mathbf{n}=\mathbf{9 8 3})\end{array}$ \\
\hline Nausea & $97(9.9)$ & $103(10.5)$ \\
Headache & $69(7.1)$ & $66(6.7)$ \\
Vomiting & $45(4.6)$ & $46(4.7)$ \\
Cellulitis & $37(3.8)$ & $32(3.2)$ \\
Diarrhea & $36(3.7)$ & $32(3.2)$ \\
Constipation & $33(3.4)$ & $38(3.9)$ \\
Infusion site extravasation & $33(3.4)$ & $33(3.4)$ \\
Pyrexia & $30(3.1)$ & $32(3.1)$ \\
Pruritus & $29(3.0)$ & $73(7.4)$ \\
Abscess on limb & $27(2.8)$ & $13(1.3)$ \\
Alanine aminotransferase & $27(2.8)$ & $15(1.5)$ \\
elevation & & \\
Dizziness & $26(2.7)$ & $26(2.6)$ \\
Infusion site phlebitis & $24(2.5)$ & $15(1.5)$ \\
\hline
\end{tabular}

with vancomycin) and in those hospitalized for treatment ( $60.5 \%$ with oritavancin; $63.6 \%$ with vancomycin). ${ }^{34}$

\section{Pharmacoeconomic considerations}

Oritavancin has shown comparable clinical response rates compared to vancomycin in the management of ABSSSI. Cost information was not reported, and pricing information does not yet appear to be available. The less frequent administration required for oritavancin, and the lack of need for serum level monitoring, would make it possible to treat some of these infections on an outpatient basis, thereby defraying some of the direct costs of the drug.

Given the efficacy and safety data accumulated to date, a single $1,200 \mathrm{mg}$ dosing strategy could offer an important therapeutic advantage in the treatment of ABSSSI. In addition to its clinical benefit and its elimination of patient compliance issues, a single-dose regimen could also offer the potential to decrease length of hospital stay, thus sparing healthcare costs and the risk of further clinical complications.

However, the longer duration of action may prove to be a safety concern, since any toxic effect or allergic reaction may continue for weeks until the agent has been cleared. The long half-life raises concerns as well about the emergence of resistance, particularly when the concentration of the drug falls below MIC for the causative pathogen. Similarly, the inability to "step down" to a beta-lactam antibiotic once the possibility of MRSA infection has been ruled out has the potential to result in increased microbial resistance. On the other hand, the multiple mechanisms of action of oritavancin are expected to be protective against the development of resistance during treatment.

\section{Conclusion}

Oritavancin seems to be an effective one-dose treatment for ABSSSI. The long half-life, multiple mechanisms of action, possibility for outpatient therapy, and favorable safety profile are all desirable features of this new lipoglycopeptide. Future clinical trials are needed to better define the safety and efficacy profiles, especially in sicker patients and for more serious infections, where the need to improve management and reduce costs is great.

It is also important to keep in mind that comparing oritavancin to vancomycin is not always commensurate with standard practice. For example, in patients with MSSA infections, beta-lactams are the preferred treatment. At this point, it is not clear how oritavancin would fare when compared to standard therapy with beta-lactam antibiotics.

Finally, further studies are needed to determine whether treatment with oritavancin is effective for other infections, such as bacteremia, osteomyelitis, and prosthetic joint infections.

\section{Disclosure}

The authors report no conflicts of interest in this work.

\section{References}

1. Kim SJ, Cegelski L, Stueber D, et al. Oritavancin exhibits dual mode of action to inhibit cell-wall biosynthesis in Staphylococcus aureus. $J$ Mol Biol. 2008;377:281-293.

2. Arhin FF, Sarmiento I, Parr TR Jr, Moeck G. Mechanisms of action of oritavancin in Staphylococcus aureus. Presented at: 47th Interscience Conference on Antimicrobial Agents and Chemotherapy; 2007; Chicago, IL.

3. Belley A, Neesham-Grenon E, Arhin FF, McKay GA, Parr TR Jr, Moeck G. Assessment by time-kill methodology of the synergistic effects of oritavancin in combination with other antimicrobial agents against Staphylococcus aureus. Antimicrob Agents Chemother. 2008;52: 3820-3822.

4. Belley A, Neesham-Grenon E, McKay G, et al. Oritavancin kills stationary-phase and biofilm Staphylococcus aureus cells in vitro. Antimicrob Agents Chemother. 2009;53:918-925.

5. McKay GA, Beaulieu S, Belley A, Arhin FF, Parr TR Jr, Moeck G. In vitro time kill studies of oritavancin against drug-resistant isolates of Staphylococcus aureus and enterococci. Presented at: 47th Interscience Conference on Antimicrobial Agents and Chemotherapy; 2007; Chicago, IL.

6. Lehoux D, Arhin FF, Fadhil I, et al. Oritavancin demonstrates rapid and sustained bactericidal activity in the rat granuloma pouch model of Staphylococcus aureus infection. Presented at: 46th Interscience Conference on Antimicrobial Agents and Chemotherapy; 2006; San Francisco, CA.

7. Van Bambeke F, Carryn S, Seral C, et al. Cellular pharmacokinetics and pharmacodynamics of the glycopeptide antibiotic oritavancin (LY333328) in a model of J774 mouse macrophages. Antimicrob Agents Chemother. 2004;48:2853-2860.

8. Rodvold KA, Gotfried MH, Loutit JS, Porter SB. Plasma and intrapulmonary concentrations of oritavancin and vancomycin in normal healthy adults. Presented at: 14th European Congress of Clinical Microbiology and Infectious Diseases; 2004; Prague. 
9. Belley A, Neesham-Grenon E, Parr TR Jr, Moeck G. Pharmacokinetic concentrations of oritavancin kill stationary-phase and biofilm Staphylococcus aureus in vitro. Presented at: 47 th Interscience Conference on Antimicrobial Agents and Chemotherapy; 2007; Chicago, IL.

10. Darouiche RO. Treatment of infections associated with surgical implants. N Engl J Med. 2004;350:1422-1429.

11. Lemaire S, Kosowska-Shick K, Julian K, Tulkens PM, Van Bambeke F, Appelbaum PC. Activities of antistaphylococcal antibiotics towards the extracellular and intraphagocytic forms of Staphylococcus aureus isolates from a patient with persistent bacteraemia and endocarditis. Clin Microbiol Infect. 2008;14:766-777.

12. Stewart PS, Costerton JW. Antibiotic resistance of bacteria in biofilms. Lancet. 2001;358:135-138.

13. Bhavnani SM, Owen JS, Loutit JS, Porter SB, Ambrose PG. Pharmacokinetics, safety, and tolerability of ascending single intravenous doses of oritavancin administered to healthy human subjects. Diagn Microbiol Infect Dis. 2004;50:95-102.

14. Chien J, Allerheiligen S, Phillips D, Cerimele B, Thomasson HR. Safety and pharmacokinetics of single intravenous doses of LY333328 diphosphate (glycopeptide) in healthy men. Presented at: 38th Interscience Conference on Antimicrobial Agents and Chemotherapy; 1998; San Francisco, CA.

15. Rubino CM, Van Wart SA, Bhavnani SM, Ambrose PG, McCollam JS, Forrest A. Oritavancin population pharmacokinetics in healthy subjects and patients with complicated skin and skin structure infections or bacteremia. Antimicrob Agents Chemother. 2009;53: 4422-4428.

16. Fetterly GJ, Ong CM, Bhavnani SM, et al. Pharmacokinetics of oritavancin in plasma and skin blister fluid following administration of a 200-milligram dose for 3 days or a single 800-milligram dose. Antimicrob Agents Chemother. 2005;49:148-152.

17. Belley A, Arhin FF, Moeck G. Oritavancin does not antagonise the activity of common antibacterial agents for Gram-positive and Gram-negative infections. Presented at: 24th European Congress on Clinical Microbiology and Infectious Diseases; 2014; Barcelona.

18. Rowe PA, Brown TJ. Protein binding of 14C-oritavancin. Presented at: 41 st Interscience Conference on Antimicrobial Agents and Chemotherapy; 2001; Chicago, IL.

19. Lehoux D, Okusanya OO, Laquerre K, Forrest A, Ostiguy V, Bhavnani SM. PK-PD of oritavancin (ORI) against Streptococcus pneumoniae (SP) in a murine-pneumonia infection model. Presented at: 47th Interscience Conference on Antimicrobial Agents and Chemotherapy; 2007; Chicago, IL.

20. Poulakou G, Giamarellou H. Oritavancin: a new promising agent in the treatment of infections due to Gram-positive pathogens. Expert Opin Investig Drugs. 2008;17:225-243.

21. Sahm DF, Draghi DC, Moeck G, Arhin FF. Longitudinal study of the activity of oritavancin (ORI) against Staphylococcus aureus (SA) from Europe (EU) between 2011 and 2013. Presented at: 24th European Congress on Clinical Microbiology and Infectious Diseases; 2014; Barcelona.

22. Mendes RE, Farrel DJ, Flamm RK, Sader HS, Jones RN. Activity of oritavancin and comparator agents against multidrug-resistant staphylococcal and streptococcal isolates responsible for documented infections in European hospitals (2011-2013). Presented at: 24th European Congress on Clinical Microbiology and Infectious Diseases; 2014; Barcelona.

23. Mendes RE, Farrel DJ, Streit JM, Jones RN. Current analysis of oritavancin potency when tested against vancomycin-resistant/susceptible enterococcal clinical isolates recovered from European medical centres (2009-2013). Presented at: 24th European Congress on Clinical Microbiology and Infectious Diseases; 2014; Barcelona.

24. Morrissey I, Seifert H, Canton R, et al; Oritavancin Study Group. Activity of oritavancin against methicillin-resistant staphylococci, vancomycin-resistant enterococci and $\beta$-haemolytic streptococci collected from western European countries in 2011. J Antimicrob Chemother. 2013;68:164-167.
25. Arhin FF, Sarmiento I, Moeck G. In vitro activities of oritavancin and comparators against meticillin-resistant Staphylococcus aureus (MRSA) isolates harbouring the novel $\mathrm{mecC}$ gene. Int $J$ Antimicrob Agents. 2014;44:65-68.

26. Mendes RE, Flamm RK, Sader HS, Jones RN. Oritavancin activity tested against Staphylococcus aureus and $\beta$-haemolytic streptococci causing skin and soft tissue infections in European Union and other countries (2010-2012). Presented at: 23rd European Congress on Clinical Microbiology and Infectious Diseases; 2013; Berlin.

27. Deane J, Opeila C, Moeck G, Arhin FF, Sahm DF. Activity of oritavancin against European bacterial pathogens associated with skin/wound and soft tissue infections and bacteraemia. Presented at: 23rd European Congress on Clinical Microbiology and Infectious Diseases; 2013; Berlin.

28. Linden PK. Vancomycin resistance: are there better glycopeptides coming? Expert Rev Anti Infect Ther. 2008;6:917-928.

29. Okusanya OO, Lehoux D, Van Wart SA, et al. Pharmacokinetics and pharmacodynamics of oritavancin against Staphylococcus aureus in a neutropenic murine thigh-infection model. Presented at: William A Craig Symposium of the International Society of Anti-infective Pharmacology; 2008; Madison, WI.

30. Forrest A, Cadieux C, Lehoux D, et al. Efficacy of oritavancin (ORI) in the mouse bacteremia model. Presented at: 48th Interscience Conference on Antimicrobial Agents and Chemotherapy/Infectious Diseases Society of America 46th Annual Meeting; 2008; Washington, DC.

31. Kaatz GW, Seo SM, Aeschlimann JR, Houlihan HH, Mercier RC, Rybak MJ. Efficacy of LY333328 against experimental methicillinresistant Staphylococcus aureus endocarditis. Antimicrob Agents Chemother. 1998;42:981-983.

32. Saleh-Mghir A, Lefort A, Petegnief Y, et al. Activity and diffusion of LY333328 in experimental endocarditis due to vancomycin-resistant Enterococcus faecalis. Antimicrob Agents Chemother. 1999;43: 115-120.

33. Dunbar LM, Milata J, McClure T, Wasilewski MM; SIMPLIFI Study Team. Comparison of the efficacy and safety of oritavancin front-loaded dosing regimens to daily dosing: an analysis of the SIMPLIFI trial. Antimicrob Agents Chemother. 2011;55:3476-3484.

34. Corey GR, Kabler H, Mehra P, et al; SOLO I Investigators. Single-dose oritavancin in the treatment of acute bacterial skin infections. $N$ Engl J Med. 2014;370:2180-2190.

35. Wasilewski MM, Disch DP, McGill JM, Harris HW, O'Riordan WD, Zeckel ML. Equivalence of shorter course therapy with oritavancin vs. vancomycin/cephalexin in complicated skin/skin structure infections. Presented at: 41 st Interscience Conference on Antimicrobial Agents and Chemotherapy; 2001; Chicago, IL.

36. Giamarellou H, O'Riordan WD, Harris HW, Owen JS, Porter SB, Loutit JS. Phase III trial comparing 3-7 days of oritavancin vs 10-14 days of vancomycin/cephalexin in the treatment of patients wiht complicated skin and skin structure infections (cSSI). Presented at: 43rd Interscience Conference on Antimicrobial Agents and Chemotherapy; 2003; Chicago, IL.

37. Moriarty SR, Wasilewski MM, Rosen AS, Perry M. Incidence of histamine-like infusion reactions in 2 Phase III studies comparing oritavancin and vancomycin in the treatment of complicated skin and skin structure infections. Presented at: 48th Interscience Conference on Antimicrobial Agents and Chemotherapy; 2008; Washington, DC.

38. Moriarty SR, Wasilewski MM, Rosen AS, Perry M. Safety of oritavancin versus vancomycin for treatment of patients with complicated skin and skin-structure infections. Presented at: 19th European Congress on Clinical Microbiology and Infectious Diseases; 2009; Helsinki.

39. Friedman HL, Moriarty SR, Hund ME, Lee SK, Mason JW, Moon TE. A Phase I, double-blind, randomized, placebo- and postive-controlled, single dose, parallel design trial to assess the potential electrocardiographic effects of oritavancin in healthy adults. Presented at: 48th Interscience Conference on Antimicrobial Agents and Chemotherapy; 2008; Washington, DC.

40. Targanta Therapeutics Corporation. NUVOCID ${ }^{\circledR}$ (oritavancin diphosphate for injection) for Treatment of Complicated Skin and Skin Structure Infections. Available from: http://www.fda.gov/ohrms/dockets/ac/08/ briefing/2008-4394b2-04-Targanta.pdf. Accessed January 20, 2015. 
Core Evidence

\section{Publish your work in this journal}

Core Evidence is an international, peer-reviewed open-access journal evaluating the evidence underlying the potential place in therapy of drugs throughout their development lifecycle from preclinical to postlaunch. The focus of each review is to evaluate the case for a new drug or class in outcome terms in specific indications and patient groups.

The manuscript management system is completely online and includes a very quick and fair peer-review system, which is all easy to use. Visit http://www.dovepress.com/testimonials.php to read real quotes from published authors.

Submit your manuscript here: http://www.dovepress.com/core-evidence-journal 